http://dx.doi.org/10.5007/2175-7968.2013v2n32p227

\title{
O ETHOS DO DICIONARISTA, UM OLHAR SOBRE O PREFÁCIO
}

\author{
Silvia Oliveira da Rosa Fernandes \\ Colégio Pedro II \\ srosa2809@gmail.com
}

Resumo: As ideias que habitam este texto tiveram como primeira morada a tese Vozes na colônia, um estudo discursivo sobre os dicionários gerais de língua, recentemente defendida. A pesquisa buscava trilhar, pelo viés da modalização nas acepções dos verbetes, os caminhos pelos quais diferentes vozes atravessam a trama discursiva dos dicionários gerais de língua no corpus constituído pelos dicionários Houaiss (2009) e Aurélio (2010), em suas edições mais recentes, já adequadas ao novo acordo. Ao buscar essas vozes, tentamos entender o dicionário como um gênero que é múltiplo mesmo em sua essência, posto que agrega outros gêneros, como verbetes, prefácio, bibliografia, apresentação. Também nos serviu de norte o conceito de que, como todo gênero, o dicionário é um construto social, que se ergue na confluência das necessidades de comunicação e possui regras de um contrato, que se estabelece, no seu caso, entre autor (dicionarista) e leitor (consulente). As duas obras que serviram de corpus para pesquisa, e cujos prefácios observaremos aqui, são resultado de um trabalho forjado em equipe, de modo que o nome dos autores constitui uma chancela de qualidade em vez de marcar a autoria do produto. Assim, entendendo que o sujeito produtor do enunciado não é único, estabelecemos o dicionarista como uma entidade discursiva e delineamos seu ethos por meio das características da obra lexicográfica e do seu produtor pinceladas em diferentes textos metalexicográficos, como os de Margarita Correia (2009), Francisco da Silva Borba (2003), Maria Teresa C. Biderman (1984, 1998), José Horta Nunes (2002), Claudia Xatara (2011) e Hebert Welker (2004, 2006). Além da metalexicografia, nos guiaram os estudos de Dominique Maingueneau (1997, 2000), Patrick Charaudeau e Maingueneau (2006) e Ruth Amossy (2005) sobre polifonia e ethos discursivo. Partindo do que se diz do dicionário para dentro dele, no prefácio, podemos observar que regras do contrato se aplicam e como se delineiam 
para o consulente, nos textos de apresentação, os dicionaristas e, como consequência, suas obras. Nos prefácios que analisamos aqui, vemos o dicionarista como uma figura de autoridade da língua, sábio, estudioso, confiável, pesquisador meticuloso e criterioso, modestamente retratado quando fala de si mesmo, grandemente enobrecido quando retratado por outro.

Palavras-chave: Metalexicografia. Ethos. Dicionário

\title{
THE LEXICOGRAPHER'S ETHOS, A GLANCE TOWAR- DS THE PREFACE
}

\begin{abstract}
The ideas contained in this text were first seen in the recently presented essay Vozes na colônia, um estudo discursivo sobre os dicionários gerais de língua. The research aimed to track, through the approach of modalization in the definitions of entries, the ways by which the different interpretations interfere in the discourse of the general language dictionaries in the corpus constituted by Houaiss (2009) and Aurélio (2010) dictionaries, in their most recent versions customized according to the new spelling agreement. By researching for such interpretations, we tried to understand the dictionary as a genre which is multiple even in its essence, as it gathers other genres such as the entries, the preface, the bibliography and the presentation. We also made use of the concept that like any other genre, the dictionary is a social construction, which emerges from the communication needs of a contract that is established, in this case, between the author (lexicographer) and the reader (consultant). Both publications were used as corpus for the research, and their prefaces, as we will observe here, are the result of a team work, in such a way that the name of the authors forms an assurance of quality instead of registering the authorship of the product. Thus, seeing that there is not only one producer of the work, we established the lexicographer as a communicative entity and outlined its ethos through the features of the lexicographical work and its producer in different meta lexicographic texts, such as the ones by Margarita Correia (2009), Francisco da Silva Borba (2003), Maria Teresa C. Biderman (1984, 1998), José Horta Nunes (2002), Claudia Xatara (2011) and Hebert Welker $(2004,2006)$. Besides the meta lexicography, we were guided by the studies of Dominique Maingueneau (1997, 2000), Patrick Charaudeau e Maingueneau (2006) and Ruth Amossy (2005) on polyphony and communicative ethos . Starting from what is stated about the dictionary to what is inside it, the preface, we could observe which rules of contract are applied and how they are outlined for the
\end{abstract}


consultant in their presentation texts, the lexicographers and as a result, their work. In the prefaces here analyzed, the lexicographer can be seen as the figure of authority in the language, wise, diligent, reliable, discerning and overcareful researcher, humbly portrait when he talks about himself, but highly glorified when portraited by somebody else.

Keywords: Metalexicography. Ethos. Dictionary

\section{O dicionário como gênero}

Diferentemente da maioria dos gêneros, estabelecidos por suas características relacionadas a conteúdos e propriedades funcionais, estilo e composição, o dicionário tem características formais bem marcadas, tanto na macro quanto na microestrutura. Sua organização de encaixe (de palavras na macroestrutura e de acepções na microestrutura) cumpre as características de um texto-colônia1, uma espécie de texto agregador cuja organização não se faz, como na maioria dos textos, pelo viés semântico, já vez que a tessitura se estabelece por numeração, alfabetação e suas partes, autônomas, podem ser deslocadas no texto ou usadas de forma independente. De fato, o dicionário, em sua gênese, segue na contramão do dinamismo da língua, quando a congela em fatias, de alfabetação, de verbetes, de significado, de uso, o que - vale ressaltar - não deve ser visto como defeito, apenas como característica peculiar do gênero.

A fórmula de encaixe é produtiva para a necessidade de uso pontual, como ferramenta de apoio na produção de outros textos, o que prevê uma técnica de pesquisa superficial até o lexema que o consulente procura e que se materializa em outro gênero textual, o verbete, onde ocorrerá a leitura detalhada. Usado em casos pontuais, como material de apoio, o dicionário não é lido como um todo e possui papel de autoridade no sentido de que é usado para tirar dúvidas, para suprimir erros, para melhorar a produção de outro texto.

Além de ser um gênero agregador de unidades, a tipologia do dicionário é múltipla, há os especializados, gerais, de uma língua, 
de mais de uma língua, de sinônimos e antônimos, onomasiológicos (que partem da ideia para a palavra) ou semasiológicos (que partem das palavras para as ideias). Nesse ponto, esclarecemos que nos referirmos neste estudo a dois dicionários semasiológicos monolíngues do português editados no Brasil, porque entendemos que é o dicionário geral de língua a fonte de toda a família de obras lexicográficas e que, embora não seja o carro-chefe do lucro, é sem dúvida a fonte de referência para toda a malha editorial.

\section{Ethos discursivo}

O ethos discursivo é um fenômeno que revela a personalidade do enunciador por meio da enunciação. $\mathrm{O}$ uso desse termo remete à retórica da Antiguidade Clássica. Na argumentação grega, o logos consistia da razão, usada na seleção das ideias, na lógica da argumentação, o pathos consistia da emoção, expressa pelo orador ou despertada na plateia, e o ethos era a imagem criada pelo orador para conferir autoridade e coerência ao seu discurso, era a roupa, a personagem discursiva evocada para argumentar.

Na Análise do Discurso, o ethos é um fenômeno discursivo por meio do qual um enunciador constitui uma imagem, geralmente de autoridade perante o que diz, não apenas pelas ideias que veicula na mensagem. Esse enunciador, legitimado também pela maneira de ser e de dizer, configura-se na enunciação como fiador, constituído de caráter (jeito de ser, personalidade) e corporalidade (maneira de portar-se, vestir-se, falar, movimentar-se no espaço social) no jogo enunciativo. Para essa legitimação ser eficaz, o ethos deve agir em consonância com as regras do gênero textual e do contrato de comunicação em determinado contexto, de modo que o interlocutor possa incorporar esse ethos quando no ato comunicativo. Dessa forma também consideramos o texto escrito, porque, apesar da distância entre os interlocutores, o texto é escrito para ser lido por alguém, que só materializará as relações de significado traçadas pelo autor no resgate das suas próprias vivências e das sugestões do interlocu- 
tor, validando ou não os enunciados. Dessa forma, o enunciador do dicionário estabelece uma série de elementos na sua enunciação que configuram sua personalidade, que conferem um tom ao que é dito.

É na busca desse tom que percorremos os prefácios, tentando identificar elementos que nos deem pistas das regras do contrato de comunicação e do ethos tanto do dicionarista quanto dos consulentes. Nesse panorama dos prefácios e apresentações, contaremos com o tom laudatório às obras e aos seus autores, especialmente nas marcas de sua produção intelectual e, de forma poética, no seu amor às letras e ao idioma. É no prefácio também que se anunciam critérios de registro e inclusão de palavras e a noção de língua que norteia a obra.

\section{O dicionarista e o leitor}

A metalexicografia nos ajuda a entender os dicionários em vários de seus aspectos, como produção e recepção da obra. Assim, a partir de textos metalexicográficos e entendendo que tanto o dicionarista quanto o consulente são entidades discursivas ${ }^{2}$, estabelecemos algumas regras simples, enunciadas em primeira pessoa, que nos norteiam na leitura das obras e dos seus prefácios. A seguir estão duas tabelas com essas regras e alguns comentários.

\section{DICIONARISTA}

Sou o responsável por registrar o patrimônio cultural coletivo.

O dicionário deve conter o léxico de uma língua com a maior abrangência possível (considerados os limites de publicação, o recorte sincrônico ou diacrônico, o corpus etc.) e com a devida precisão, para que estejam nele escolhas relevantes para representar esse patrimônio. Essa representação passa por privilegiar certas áreas reconhecidamente importantes para a sociedade, como hoje são a Medicina, a Tecnologia e Biologia. 


\section{Sou o porta-voz e represen- tante da variante aceita $e$ valorizada na comunidade. Portanto, sou indiretamen- te professor de uma condu- ta linguística que reflete a norma social, observada em parte pela forma como estruturo meus enuncia- dos, pautada pela variante padrão.}

Registro os usos de menos prestígio, sinalizando ao leitor, porque o dicionário deve registrar palavras de todas as variantes.

Registro também palavras antigas, parte de um acervo que muitos não dominam mais.

Sou um observador atento da cultura, da sociedade e da linguagem.
Como o dicionário é fonte de referência, o dicionarista deve usar a variante padrão no seu discurso, abrindo mão dela apenas em situações especiais, como os exemplos, abonações (porque o enunciado é de outro), no registro das entradas de calão e informais, na sinonímia (porque a descrição pode ser formal, mas os sinônimos mais expressivos para uma palavra às vezes são os de mesmo registro). Ajudar o consulente a manejar a língua em todas as suas nuances é uma das funções pedagógicas que o dicionarista exerce.

Apesar de fazer uso da variante socialmente prestigiada, o lexicógrafo representa uma coletividade e sua diversidade, por isso deve inserir usos menos conceituados e sinalizar isso ao leitor, para que fique marcado apenas como registro e não como parte do seu discurso.

A diversidade dos registros lexicográficos atravessa as estratificações sociais e as fronteiras do tempo, porque a língua avança e se modifica também segundo esses critérios. $\mathrm{O}$ registro de palavras antigas é mais comum nos tesauros, obras cuja função é preservar o patrimônio linguístico, mas ocorre também no dicionário geral de língua, pois o consulente quer encontrar nessa obra termos antigos com os quais tenha contato.

A seleção de entradas da macroestrutura, a redação de exemplos, a seleção de abonações, as marcas de uso, as referências de registro seguem alguns critérios definidos pela sensibilidade do dicionarista e algumas decisões levam a registros que têm por objetivo manter a coerência da obra, como ocorre, por exemplo, com a delimitação das fronteiras entre polissemia e homonímia. 
Oriento o leitor a usar os meios de expressão semânticos e pragmáticos mas também fonéticos, fonológicos, sintáticos e morfológicos.

O dicionário guarda conhecimentos técnicos preciosos, por isso uso a descrição científica do referente.

Para redigir verbetes ou incluir palavras e informações, baseio-me em ocorrências e na necessidade de designar uma determinada realidade e isso definirá o tipo de dicionário a ser elaborado.

Não tenho a liberdade do enciclopedista, devo limitar-me à definição e estou em uma estrutura formal mais rígida.
Embora seja função do dicionário o registro do léxico e seja função da gramática o registro das regras, os dicionários costumam fornecer informações sobre o sistema linguístico, especialmente as que costumam gerar dúvida, como ortoépia, divisão silábica, flexão verbal e nominal, regência verbal e nominal.

Detentor do saber cultural coletivo, o dicionário armazena no léxico comum da língua palavras e termos técnicos, como ecossistema, biodiversidade, camada de ozônio, radiação ultravioleta, DNA, HIV ${ }^{3}$ empiriocriticismo, megaelétron-volt, méson, antiquark. Para definir essas palavras, o dicionarista recorre à descrição científica do referente, para manter a propriedade e a precisão da definição, embora a obra se destine a toda a comunidade linguística.

Para selecionar algumas entradas entre as muitas ocorrências que emergem das mais variadas situações de comunicação, o dicionarista precisa ter em mente que realidade precisa retratar: mais técnica, mais popular, mais arcaica, mais voltada ao uso. Com isso, são privilegiadas certas áreas do saber, porque a sociedade as valoriza e o dicionarista deve corresponder a essa necessidade de registro. Aliado a essa orientação, pode haver um corpus com indicação da frequência das ocorrências, critério que pode nortear ou definir a macroestrutura, especialmente em dicionários de usos.

O enciclopedista pode construir um texto de sequência enunciativa sintaticamente completa, o dicionarista tem a incumbência de definir o termo atrelado a uma estrutura enunciativa quebrada de mesma classe e a dados linguísticos e referenciais. 


\begin{tabular}{|c|c|}
\hline $\begin{array}{l}\text { Minha produção resulta em } \\
\text { uma fonte confiável de in- } \\
\text { formação. }\end{array}$ & $\begin{array}{l}\text { Estar no dicionário é algo que confere a uma } \\
\text { palavra um status diferente de outros vocábulos, } \\
\text { por isso o dicionarista é também um repositório } \\
\text { de informação e referência de credibilidade. }\end{array}$ \\
\hline $\begin{array}{l}\text { É natural basear-me no tra- } \\
\text { balho de outros dicionaris- } \\
\text { tas e seguir suas pesquisas. } \\
\text { Usar corpus é também uma } \\
\text { forma de observar a língua } \\
\text { e registrar seus usos. }\end{array}$ & $\begin{array}{l}\text { Se o dicionarista é voz de autoridade para deci- } \\
\text { sões linguísticas e registro do léxico, é natural } \\
\text { que os mais tradicionais sejam seguidos em al- } \\
\text { guns registros pelos posteriores, uma vez que é } \\
\text { o dicionário também um repositório da tradição } \\
\text { linguística. É importante, ainda, ter acesso ao } \\
\text { corpus porque, apesar de normativo, o dicioná- } \\
\text { rio também é forjado pelo uso da língua num } \\
\text { recorte qualquer, por exemplo, cronológico. }\end{array}$ \\
\hline
\end{tabular}

\section{LEITOR}

$\mathrm{Eu}$ quero encontrar no dicionário aquilo que fui procurar.
Procuro aval para empregar uma palavra ou dirimir uma dúvida sobre o domínio a que pertence.
Satisfazer a esse critério básico do leitor é a busca virtual de todo dicionarista, apesar de sua concretização ser impraticável. Ao fazer uma pesquisa de satisfação com usuários de dicionários, Xatara (2011, p. 163-170) registrou como queixa básica obras que não respondem às dúvidas, seja de significado, de regência, de sinonímia, de marcas de uso.

O leitor busca o dicionário como uma fonte de autoridade para respaldar o uso que deseja fazer, mas para o qual se sente inseguro. Além disso, o avanço tecnológico, a facilidade de acesso à informação, a dinamicidade dos meios de comunicação, o avanço nas pesquisas científicas, a redefinição das relações sociais, entre outros fatores, mudam o comportamento das pessoas e as expõem a contato com diversas realidades, culturas, pessoas. Essa riqueza de experiências influencia o léxico e a circulação do saber e das diferentes experiências em meios leigos. Nesse contexto, o dicionário pode auxiliar na apropriação desse acervo novo e regular o uso adequado dos termos técnicos ou neologismos. 


\begin{tabular}{|c|c|}
\hline $\begin{array}{l}\text { Eu volto periodicamen- } \\
\text { te ao dicionário e ajudo a } \\
\text { sociedade a consolidar os } \\
\text { vocábulos e seus usos na } \\
\text { memória. }\end{array}$ & $\begin{array}{l}\text { A língua muda, sempre, e o dicionário crista- } \\
\text { liza usos ou expande inovações, que o falante } \\
\text { traz e também reproduz a partir do registro } \\
\text { na obra. Como a língua é um sistema vivo, } \\
\text { em mutação constante e irrefreável, o dicio- } \\
\text { nário pode funcionar tanto como um elemen- } \\
\text { to normativo, conservador da tradição, quan- } \\
\text { to avançado, voz da inovação. Qualquer que } \\
\text { seja o caso, a busca no dicionário e a repro- } \\
\text { dução do que nele está se faz em parte pela } \\
\text { colaboração da comunidade em passar adian- } \\
\text { te e efetivamente fazer uso do material de } \\
\text { consulta. Além disso, é possível fazer contri- } \\
\text { buições diretas, como aquelas a que Aurélio } \\
\text { agradece no prefácio da primeira edição e as } \\
\text { que são feitas no Aulete Digital e avaliadas } \\
\text { pela equipe de redatores. }\end{array}$ \\
\hline $\begin{array}{l}\text { Eu me reconheço como } \\
\text { membro de uma comuni- } \\
\text { dade, como falante, como } \\
\text { parte de uma cultura. }\end{array}$ & $\begin{array}{l}\text { Embora o dicionário respalde o uso de uma } \\
\text { determinada variante e seja porta-voz desse } \\
\text { segmento, não se exime de registrar todas } \\
\text { quantas forem as variantes para, apesar de } \\
\text { seu caráter estático, tentar abranger a dina- } \\
\text { micidade e os usos da língua. Dessa forma, } \\
\text { o leitor, ao consultar uma obra, deve se ver } \\
\text { nela. }\end{array}$ \\
\hline $\begin{array}{l}\text { Pela norma descrita, posso } \\
\text { analisar socialmente o com- } \\
\text { portamento do outro, alguns } \\
\text { usos são aceitos, outros são } \\
\text { condenados e descartados. }\end{array}$ & $\begin{array}{l}\text { Apesar de se ver nessa norma padrão, como a } \\
\text { obra expõe essa variante, por meio do caráter } \\
\text { normativo do dicionário, o leitor pode observar } \\
\text { os usos que escapam a esse padrão ou estão } \\
\text { adequados a ele e, assim, medir os outros se- } \\
\text { gundo esse padrão, acatando ou rejeitando os } \\
\text { usos que observa. }\end{array}$ \\
\hline
\end{tabular}




\begin{tabular}{|c|c|}
\hline $\begin{array}{l}\text { Geralmente dou mais im- } \\
\text { portância ao número de en- } \\
\text { tradas do que aos critérios } \\
\text { de sua seleção, mas também } \\
\text { é importante o dicionário } \\
\text { ser prático, coerente e ter } \\
\text { boa diagramação. }\end{array}$ & $\begin{array}{l}\text { Como o léxico é um conjunto de palavras de } \\
\text { extensão inesgotável, fica ao leitor a impressão } \\
\text { de que, quanto mais palavras registrar, melhor } \\
\text { será a obra, o que se observa nas campanhas } \\
\text { de divulgação das obras que trazem na capa os } \\
\text { números resgatando a máxima de que "os núme- } \\
\text { ros são argumentos irrefutáveis". Se, em alguns } \\
\text { casos, está registrado um cognato, por exemplo } \\
\text { o verbo, não é seguro para o falante comum } \\
\text { formar o adjetivo em - vel, sob pena de cunhar } \\
\text { um neologismo quando pode haver termo mais } \\
\text { próprio já registrado na obra. Por isso, reduzir a } \\
\text { macroestrutura a certos cognatos é uma decisão } \\
\text { econômica para os lexicógrafos, mas que pode } \\
\text { não se mostrar eficaz para o consulente. }\end{array}$ \\
\hline $\begin{array}{l}\text { Eu ajudo a definir a exten- } \\
\text { são da obra, os critérios } \\
\text { para registro e a função do } \\
\text { dicionário. }\end{array}$ & $\begin{array}{l}\text { Pensando num leitor prototípico (técnico, lei- } \\
\text { go, letrado, pouco escolarizado), o dicionarista } \\
\text { norteia suas decisões. Por exemplo, se o leitor } \\
\text { é despreparado, tem dificuldade para encontrar } \\
\text { formas flexionadas muito diferentes formal- } \\
\text { mente das canônicas, isso pode influenciar na } \\
\text { entrada de uma remissão. }\end{array}$ \\
\hline
\end{tabular}

\section{Dicionário Aurélio da língua portuguesa (DALP)}

Em edição comemorativa do centenário de Aurélio Buarque de Holanda, edição com a qual optamos por trabalhar, o DALP traz um prefácio à quinta edição mais conciso que o da primeira, que é mas o mais extenso entre as edições. Observando basicamente a edição com a qual trabalhamos, mas recorrendo também aos prefácios anteriores, especialmente os escritos pelo autor $\left(1^{\mathrm{a}}\right.$ e $2^{\mathrm{a}}$ edições), vemos algumas das características acima citadas.

Especialmente por ser uma edição comemorativa do centenário do nascimento de Aurélio Buarque de Holanda, é mais do que legítimo o prefácio à quinta edição aludir ao passado do professor que dá nome à obra, aliás, "professor, lexicógrafo, filólogo, contista, tradutor, revisor", funções que coexistem com as de "amigo, 
marido, avô" (DALP, 2010:XI). Mas Aurélio era, antes de tudo, "brasileiro, alagoano, lusófono" (idem). Caracterizar o dicionarista nessas três esferas (humana, profissional e familiar) é marcante para dimensionar sua expressividade, não apenas pela autoridade de quem, profissionalmente, domina as técnicas de dicionarística, mas principalmente pela autoridade de quem é cidadão deste país e apaixonado pela sua língua.

É, pois, desse lugar que a obra parte, do lugar apaixonado do homem comum e altamente especializado que, por sua riqueza pessoal e intransferível, é a pessoa certa para estampar o dicionário e, como ele, suas escolhas, seus usos, seus registros, sua concepção de língua e cultura. Entretanto, essa imagem de homem grandioso não deixa de estar atrelada a uma necessidade de humanização que se opõe à grandeza da figura impoluta do sábio, que tinha "pensamento claro e redação fácil" (DALP, 2010:XI):

[...] o Aurélio dicionarista venceu o tempo e, por meio das palavras com quais sempre 'lutou' e que sempre amou, realizou o sonho do menino que cedo começou a trabalhar, para ajudar a família e, também, para poder comprar as brochuras que tanto apreciava ler. Este era o Aurélio incansável, persistente, determinado a vencer a fadiga, a posição à mesa, por mais uma palavra, mais um pouco, dizia, por amor à sua obra. (DALP, 2010:XI)

[...] Na infância humilde, no interior de Alagoas, frequentou escolas sem muitos recursos, mas já demonstrava grande inteligência e esforço, que resultavam em progresso. (DALP, 2010:IX)

É interessante observar como, no prefácio à primeira edição, o dicionarista não fala desse lugar pomposo, e sim de um lugar de modéstia, autointitulando-se "aprendiz de lexicografia" (DALP, 
2010:XV). No início do prefácio, inclusive, há uma desmistificação parcial da figura do lexicógrafo, cujo "esforço sobre-humano [...] pode terminar com as mais indesejáveis conseqüências físicas, compensação intelectual bem pouco aliciante e resultados financeiros não demasiado expressivos". (DALP, 2010:XVI). Há, também, entrelaçado nessa descrição, o caso triste e nada glorioso dos que não levaram a termo o dicionário da Academia das Ciências de Lisboa, motivo de deboche citado, inclusive, em nota. A história envolve a morte decorrente do ofício de um e a cegueira de outros dois, que tiveram como paga o esquecimento e um mero exemplar, mas, neste prefácio, foram alçados a mártires. Porém, não há apenas a desconstrução desse lugar solene, uma vez que, apesar de humanizar o dicionarista ao descrever suas mazelas, o autor o idealiza pelo empenho super-humano e pelo heroísmo do mártir.

Despido em parte da pompa que se esperaria do lexicógrafo, Aurélio fala diretamente ao leitor que isso é uma estratégia para conseguir a atenção para a leitura de um texto notadamente "não muito apetecido" (DALP, 2010:XIV) e, com isso, expõe seu conhecimento de orador na arte de seduzir a plateia. Quebrado o paradigma e angariada a simpatia do leitor pela penosa tarefa que lhe coube como o mentor da obra, Aurélio pede paciência e se mune de informações "sem divagações" (idem), o que aponta para a construção de um ethos do lexicógrafo em geral como um profissional que trabalha arduamente, nem sempre é reconhecido, mas segue heroicamente na persecução de seus objetivos.

Já na edição comemorativa, agregado ao inegável reconhecimento do homem que batiza a obra, a apresentação e o prefácio lembram a larga aceitação deste dicionário - 1 em cada 6 brasileiros possuem um exemplar do Aurélio em uma de suas versões (DALP, 2010:IX) - ao longo do lastro entre a primeira e a quinta edição: "Trinta e cinco anos de adoção em escolas, cursos, universidades, empresas, escritórios e lares [...]" (DALP, 2010:XI). Retoma-se aqui uma característica do público que não estava clara na metalexicografia em que nos apoiamos: o leitor prototípico é 
letrado, frequenta o ambiente escolar e tem como hábito consultar a obra em ambiente profissional e doméstico, cuja grande força materializa-se na palavra lar, a qual remete diretamente à instituição familiar, em detrimento de casa, que remete ao espaço físico de habitação.

Esse aspecto do ethos do leitor estudioso da língua está também na apresentação feita por Oriovisto Guimarães (DALP, 2010:IX), que reconhece o alcance do dicionário em áreas institucionalmente responsáveis pela divulgação do saber, como bibliotecas:

A palavra mestre também se aplica a inúmeras outras pessoas, que dedicam suas vidas à educação, que fazem o mesmo que um professor fez ao menino Aurélio, ao aluno dedicado: mostram o futuro, a possibilidade de alcançar o amanhã. [...] Muitas dessas pessoas, que se dedicam à educação, utilizam o dicionário para ensinar. E para aprender.

No prefácio à primeira edição, esse preparo esperado do leitor não está literalmente traduzido como na quinta, a não ser na utilidade declarada na consulta aos elementos gregos e latinos, subgrupo de verbetes ainda mais especializado. Contudo, ao passear pelas mais diferentes esferas do conhecimento linguístico (semântica, sintaxe, fonologia, morfologia), o dicionarista de certa forma pressupõe que isso faça sentido para o leitor, ao mesmo tempo em que demonstra dominar os fenômenos linguísticos. Em outras palavras, ao delimitar os critérios do dicionário, como registro de homonímia e atenção à regência verbal, o dicionarista não apenas mostra que sabe como também espera que isso seja entendido pelo leitor, ao menos para o que lê o prefácio.

Confirmamos, com esse fenômeno, outra característica do ethos do dicionarista, marcada pelo próprio Aurélio: o domínio dos fenômenos linguísticos, que o investe de autoridade suficiente para corrigir "os cochilos do Vocabulário Ortográfico de 1943" (DALP: 2010, XV), ocupando o espaço da Academia de Letras para legislar sobre a ortografia da língua, e as lacunas de obras anteriores, que, copiando umas às outras, deixaram passar 
um mundo de vocábulos e, sobretudo, de significados, vivos, de um século, de séculos, e esquecidos dos lexicógrafos, que, ao longo do tempo (com exceções, é claro), foram fazendo pouco mais do que se copiarem (o que às vezes é inevitável) [...] (DALP, 2010:XV)

Também por meio da concepção da obra e da língua, ainda nas palavras do próprio Aurélio, é possível observar características do ethos desse dicionarista, que entende a língua em suas múltiplas variantes, observando-as nos mais diferentes meios, desde os escritores (clássicos ou modernos) até a língua "dos jornais, revistas, do teatro, do rádio e televisão, ao falar do povo, aos linguajares diversos - regionais, jocosos, depreciativos, profissionais, giriescos..." (DALP, 2010:XIV), e vê na obra lexicográfica um lugar onde cabem todas essas nuances, onde podem se reconhecer todos os falantes, aspecto do ethos do leitor também observado nas leituras metalexicográficas.

Essa pluralidade de descrição já anunciada na primeira edição, como vimos acima, se repete na quinta, que busca refletir o conceito de língua como organismo vivo em movimento, embora o movimento registrado seja limitado (aquelas palavras que 'vieram para ficar'), e retratar, ainda, uma cultura múltipla, por meio de palavras de diversas áreas de conhecimento ("informática, biologia, genética, botânica, ecologia, economia, educação, pedagogia, astronomia, física, física quântica, engenharia, química, medicina, culinária, etc." - DALP, 2010:XI). Essa multiplicidade também inclui diferentes registros e empréstimos, "por não haver como fugir da influência de outros idiomas” (DALP, 2010:XI). Isso significa que língua e dicionário seguem na mesma mão da via evolutiva, pois

uma das principais funções do dicionário, se não a principal, é acompanhar a evolução da língua, numa dada época, e registrar-lhe a renovação por meio das palavras e locuções (lexias) ou das formas adotadas pelo uso. (DALP, 2010:XI) 
Concebida por um homem ao mesmo tempo inteligente e sensível, cujo legado se seguiu após sua morte, em 1989, o dicionário Aurélio busca ser uma obra contínua, já que uma língua viva precisa seguir seu curso e assim deve ser com o dicionário que a retrata. Buscando captar essas mudanças, sincrônica e diacronicamente, grosso modo, a obra busca acompanhar a evolução da língua,

ao registrar aquilo que, de caráter recente ou menos recente 'veio para ficar': o que já está assimilado, absorvido pelos diferentes falares, em diferentes níveis e usos, de uma mesma língua, seja na variante brasileira, lusa ou africana. (DALP, 2010:XI)

Neste ponto, observamos a relação da obra com a língua apenas em seu caráter descritivo, para, em seguida entender que, por questões metodológicas, a descrição pode vir aliada à prescrição: "o modo como essas palavras e locuções são consignadas, algumas vezes, sofre alteração, especialmente quando se decide uniformizar-lhes a grafia." (DALP, 2010:XI).

Porém, na apresentação da edição comemorativa, o que fica mais claro é o papel pedagógico do dicionário, pois o lexicógrafo é caracterizado sobretudo como um educador:

Esta é a $5^{\mathrm{a}}$ edição do dicionário elaborado por um professor. Sim, Aurélio Buarque de Holanda Ferreira sempre foi um professor, um educador. [...] Quando não ensinava em sala de aula, dedicava-se ao saber e à transmissão do conhecimento por outra via: a lexicografia. [...] Indiretamente, por meio de verbetes, definições, exemplos, abonações, achegas, o professor continuava ensinando. Ensinava o significado das palavras e, mais, ensinava como as usar e, até mesmo, como não usá-las. (DALP, 2010:IX)

Especialmente no DALP, a caracterização pedagógica do dicionarista e da obra entra em consonância com o Grupo Positivo, "maior grupo educacional do Brasil" (DALP, 2010:IX), e sua pre- 
ocupação social de disseminar o saber e desenvolver o país. Esse aspecto confiável é decisivo para o sucesso da obra e é esperado do leitor prototípico que confie nas informações ali presentes, como está expresso claramente na apresentação (DALP, 2010:IX):

É a obra em que o povo brasileiro confia, que deixa entrar em seu lar e participar do seu cotidiano. Conhecendo a trajetória da obra e de seu autor, essa confiança tende a aumentar, aliada, obviamente, à sua incomparável qualidade.

E é na dinâmica da interação do leitor com a obra, por meio dos questionamentos, da aprendizagem e do ensinamento que o dicionário ganha espaço na vida e no discurso do consulente: "a obra de Aurélio vive e renasce a cada consulta, a cada pergunta feita, a cada resposta dada." (DALP, 2010:XI), o que caracteriza a obra, mesmo escrita, como enunciação. Esse contato entre leitor e autor é patente também no prefácio à segunda edição, quando o autor agradece "aos leitores que [...] enviaram achegas, quer por escrito, quer de viva voz" (DALP, 2010:XVI), representando o constante e rico processo de retroalimentação da obra para o público e deste para a obra.

\section{Dicionário Houaiss da língua portuguesa (DHLP)}

Diferentemente do DALP, o DHLP não dilui a biografia de seu autor no prefácio e na apresentação. Na apresentação consta uma biografia, com as características formais do gênero, especialmente pelas datas de nascimento e morte, foto e realizações pessoais detalhadas. Essa opção traz a premissa de que expor a biografia de Antônio Houaiss basta para conferir credibilidade ao conteúdo da obra.

Nesse percurso prevalece a grandiosidade do homem, que "transcenderia o anonimato ainda aos 16 anos" e que durante "vida 
inteira marcaria sua presença com reconhecido brilho" (DHLP, 2010:V), não apenas por sua vasta produção, detalhada no texto, como também pelas mais diversas funções de destaque exercidas por ele - diplomata de carreira, ministro, presidente da Academia Brasileira de Letras, enciclopedista, tradutor, crítico literário (DHLP, 2010:V) - e pelos projetos que empreendeu ao longo da vida, por exemplo, como delegado e porta-voz brasileiro do acordo ortográfico hoje em vigor. Nesse panorama, ao contrário da apresentação do DALP, o dicionarista não é homem comum, é retratado pela grandeza de suas conquistas e, por isso, merece ser fonte confiável de informação e batizar a obra.

Essa estrutura biográfica, que vemos aqui como o cartão de visitas da obra, pois é a primeira página escrita, constitui o mesmo recurso usado na edição de 2001, de mesmo nome, mas de maior extensão. Na verdade, o que chamamos aqui de apresentação é a biografia do autor, pois, na edição maior, havia um prefácio e uma apresentação, a qual foi abolida na edição de menor porte, de 2009. No prefácio desta edição, assim como houve com o DALP, a tradição é usada como um elo de confiança entre autor e público, mas, neste caso, entra a experiência não cronológica mas sim criativa e diversificada que abrange obras de diferentes naturezas. Partindo da confiança já conquistada, o dicionarista faz um convite direto ao leitor para avaliar todas as medidas desse "novo esforço" que orientaram a produção da obra: "O fruto desse novo esforço será agora julgado por você, leitor, de quem esperamos ganhar mais uma vez a aprovação e confiança". (DHLP, 2010:V)

Nesse processo, citam-se as obras da família Houaiss, que, produzidas na esteira da primeira obra, em 2001, são "material de base para o aperfeiçoamento [dos] dicionários" (DHLP, 2009:V). Também entram como parte da valorização da obra os números, neste caso de verbetes, entradas e locuções. Em contrapartida a essa citação de números, o dicionário recorta outro nicho, preenchendo "um hiato na família dessas obras" (DHLP, 2009:V), um dicionário que não fosse "ecumenicamente lusofônico", "uma obra 
ágil e prática, mas com um número de informações maior sobre a língua do que se costuma encontrar em dicionário desta extensão." (DHLP, 2009:V). Contando, ainda, com "modernos recursos editoriais lexicográficos e uma proficiente engenharia de sistema computacional" (DHLP, 2009:V), o dicionarista inscreve sua obra num enquadre contemporâneo e moderno, trazendo para o seu fazer a tecnologia que transborda no mundo globalizado.

Observando as diferentes alusões à estrutura do dicionário editado em 2001, de maior porte, por ser a do DHLP mais concisa, é produtivo recorrer à apresentação do ainda chamado Dicionário Houaiss da língua portuguesa, em 2001, neste trabalho designado pela sigla GHLP.

A apresentação foca o processo de produção da obra, que naquele momento se apresentava ao público, esclarecendo seus três eixos norteadores (a macroestrutura ampla, a datação e o detalhamento dos elementos mórficos) e suas duas fases de produção. Como nos demais prefácios e apresentações vistos, os números são de novo um argumento eficaz para concretizar a magnitude e a seriedade da obra para o leitor. No entanto, como é obra desconhecida do público, além dos números de entradas, estão citados o tempo de redação (15 anos) e a quantidade de redatores (34) e colaboradores (43).

Em consonância com a amplitude dos números, encerra-se uma proposta de dicionário amplo, com abrangência da língua em todos os territórios onde ela é falada. Em oposição a essa amplitude está o cuidado extremo em "definir efetivamente os conceitos das palavras analisadas, em lugar de lançar mão da prática da simples sinonimização" (GHLP, 2001:XV).

Dessa opção pela perífrase e não pela sinonimização, ainda que imprecisa por conta da polissemia dos vocábulos, emerge a necessidade de um leitor prototípico dotado de uma "competência linguística" suficiente para fazer essa "decodificação semântica" e para lidar com definições extensas, além de uma série de outras "informações úteis", como 
rubricas temáticas, dados sobre regionalismo, nível de uso, estatística de emprego e registro diacrônico das acepções, sinônimos, antônimos, coletivos, notas de gramática e uso das palavras, informes onomasiológicos etc. (GHLP, 2001:XV)

Na contrapartida do papel do leitor de decodificar enunciados mais extensos, está a incumbência do dicionarista de "evitar a armadilha da sinonimização e procurar definir os reais sentidos das palavras" (GHLP, 2001:XV). Isso demanda um grau de especialização que pode levar a dificuldades para leitores não especializados na "terminologia de alguns temas, especialmente de ordem científica e tecnológica" (GHLP, 2001:XV). Dessa forma, o dicionário busca um leitor mais preparado para as descrições que produz, mas reconhece que "não há quem domine todas as temáticas nele registradas e que o problema resolve-se com uma ida a outro verbete" (GHLP, 2001:XV).

O leitor prototípico, além de ser competente no uso do código e das informações, é também múltiplo, por conta da abrangência geográfica e cronológica que a obra pretende alcançar, pois "resultou em uma obra com cerca 228.500 unidades léxicas que não privilegia determinada faixa cronológica ou geográfica da língua", uma vez que organiza as acepções por datação e registra "vocábulos da língua antiga e arcaica", além de contar com colaboradores de "Portugal, São Tomé e Príncipe, Guiné-Bissau, Cabo Verde, Angola, e Moçambique" (GHLP, 2001:XV)

É grande também a abrangência de significados considerados no registro de acepções e entradas: "obras literárias, técnicas e didáticas, além de periódicos de informação geral e de entretenimento" (GHLP, 2001:XV). Essas pesquisas citadas no GHLP incluíram o confronto com as obras de outros lexicógrafos, característica do ethos que levantamos anteriormente, e revelaram uma tendência tanto descritiva, como a dos exemplos, quanto normativa, embora esta só apareça com mais força no DHLP, quanto à padronização da ortografia: 
Quanto à ortografia, [...] este Dicionário Houaiss procurou louvar-se nas soluções dadas pela A.B.L. ao seu novo Vocabulário. Muito poucas ressalvas, mas de ordem afim, ocorreram nesse processo, como é o caso das palavras compostas que perderam seu hífens, às quais consideramos locuções substantivas enquanto o Vocabulário as classifica como substantivos tão somente.

Avançando na magnitude que o dicionário pretende alcançar, sua pretensão extrapola a função de referência para dúvidas de consulentes, pois busca ser referência dentro do próprio cenário da lexicografia mundial, como se observa no seguinte trecho:

Foi a importância da nossa língua no concerto das de maior curso de utilização que plasmou a necessidade de projetar um dicionário abrangente para ombrear como que há de mais moderno no gênero pelo mundo. [para a construção do que] Antônio Houaiss sonhou para este dicionário: um espaço de conscientização ecumênica da língua, que possibilitasse também a conquista de um novo patamar no desenvolvimento de nossa lexicografia. (GHLP, 2001:XV)

\section{6. Últimas palavras}

O que vimos aqui sobre o ethos do dicionarista por meio da observação do prefácio é a construção de uma figura ilustre, quando descrita por outros, e sem tanto brilho em sua autoavaliação. Nos dois prefácios predomina uma visão poética da figura do dicionarista, que tem definitivo papel pedagógico, além de ser um grande conhecedor do mundo e da língua, trabalhador árduo e incansável em prol da sua obra e da língua. Além disso, pudemos ver características importantes da obra e do leitor, uma vez que estão todos esses elementos entrelaçados na enunciação.

Cabe esclarecer, por fim, que não era nosso objetivo detalhar o assunto, até mesmo porque essas considerações são parte de uma pesquisa mais ampla que não tinha esse objeto como foco principal, embora essas noções tenham norteado a análise dos dados. A inten- 
ção, bem mais modesta, é promover um olhar sobre os prefácios a partir de aspectos discursivos do dicionário, pois explorá-los é um terreno produtivo de estudo. Além disso, ao observar a obra lexicográfica discursivamente

[...] de um lado, deixamos de reverenciar o dicionário [...] como monumento à língua para vê-lo como instrumento linguístico, produzido na história, em um certo momento; de outro [...], ao perder seu caráter monumental para ser objeto tangível de nossa relação com a língua na história, ele se apresenta como vestígio de nossa memória históricosocial. (ORLANDI, 2000, p. 98)

\section{Notas}

1. Para mais informações, conferir DIONISIO, Ângela Paiva. "Verbetes: um gênero além do dicionário. Ângela Paiva Dionisio". in . Gêneros textuais e ensino. Rio de Janeiro: Lucerna, 2002.

2. Usamos os estudos de Ducrot segundo os quais o sujeito falante não é uno, mas se divide em autor, locutor e enunciador.

3. Exemplos retirados de CANO, Waldenice Moreira. "Os dicionários de língua, a norma cultural e os terminologismos." In SILVIA, Maria Emília Barcelos da. (org.) Anais do Primeiro Encontro de Nacional do GT de Lexicologia, Lexicografia e Terminologia da Anpoll. Recife, 1998. 


\section{Referências}

AMOSSY, Ruth. 2005. Imagens de si no discurso $\square$ a construção do ethos. São Paulo: Contexto.

BIDERMAN, Maria Tereza C. 1984. O dicionário padrão da língua. Alfa, São Paulo, v.28 (supl.), p.27-43.

. 1998. O dicionário como norma na contemporaneidade. In SILVIA, Maria Emília Barcelos da. (org.) Anais do Primeiro Encontro de Nacional do GT de Lexicologia, Lexicografia e Terminologia da Anpoll. Recife.

BORBA, Francisco da Silva. 2003. Organização de dicionários: uma introdução à lexicografia. São Paulo: Ed. da Unesp.

CORREIA, Margarita. 2009. Os dicionários portugueses. Alfragide: Caminho.

FERREIRA, Aurélio Buarque de Holanda. 2010. Dicionário Aurélio da língua portuguesa. (coordenação de Marina Baird Ferreira e Margarida dos Anjos) Versão eletrônica. Curitiba: Positivo. 5.ed.

HOUAISS Antônio e VILLAR Mauro de Salles. Dicionário Houaiss da Língua Portuguesa. 2001. Instituto Antônio Houaiss de Lexicografia e Banco de Dados da Língua Portuguesa, Rio de Janeiro: Objetiva.

. 2009. Dicionário Houaiss da língua portuguesa. Versão eletrônica. Rio de Janeiro: Objetiva. 1. ed.

MAINGUENEAU, Dominique. 1997. Novas Tendências em Análise do Discurso. Campinas: Pontes / Ed. Unicamp. (tradução Freda Indursky)

. e CHARAUDEAU, Patrick. 2006. Dicionário de Análise do Discurso. São Paulo: Contexto. 
MOTTA, Ana Raquel e SALGADO, Luciana. (Org.). 2008. Ethos discursivo. São Paulo: Contexto.

NUNES, José Horta e PETTER, Margarida. 2002. História do saber lexical e constituição do léxico brasileiro. São Paulo: Humanitas, Campinas: Pontes.

ORLANDI, Eni Pulcinelli. Lexicografia discursiva. Alfa (São Paulo), 2000, v.44, p.97-114. Disponível em seer.fclar.unesp.br/alfa/article/view/4201/3797

WELKER, Herbert Andréas. 2004. Dicionários. Uma Pequena Introdução à Lexicografia. Brasília: Thesaurus.

. 2006. O uso de dicionários. Brasília, Thesaurus.

XATARA, Claudia, BEVILACQUA, Cleci Regina e HUMBLÉ, Philippe René Marie. 2011. Dicionários na teoria e na prática: como e para quem são feitos. São Paulo: Parábola Editorial.

Recebido em 08/12/2012

Aceito em 05/06/2013 